\title{
Direct Deposition of Crystalline Aragonite in the Controlled Biomineralization of the Calcareous Tubeworm
}

\section{OPEN ACCESS}

Edited by:

Christian Robert Voolstra, King Abdullah University of Science and Technology, Saudi Arabia

Reviewed by:

Christine Ferrier-Pagès, Centre Scientifique de Monaco,

Monaco

Steeve Comeau,

University of Western Australia, Australia

*Correspondence: Vengatesen Thiyagarajan

rajan@hku.hk;

Andrew S. Mount mount@clemson.edu

Specialty section:

This article was submitted to Marine Molecular Biology and Ecology, a section of the journal Frontiers in Marine Science

Received: 19 September 2015 Accepted: 02 November 2015 Published: 18 November 2015

Citation:

Chan VBS, Toyofuku T, Wetzel G, Saraf $L$, Thiyagarajan $V$ and Mount AS (2015) Direct Deposition of Crystalline

Aragonite in the Controlled

Biomineralization of the Calcareous Tubeworm. Front. Mar. Sci. 2:97. doi: 10.3389/fmars.2015.00097

\author{
Vera B. S. Chan ${ }^{1,2}$, Takashi Toyofuku ${ }^{3}$, George Wetzel ${ }^{4}$, Laxmikant Saraf ${ }^{4}$, \\ Vengatesen Thiyagarajan ${ }^{1 *}$ and Andrew S. Mount ${ }^{2 *}$ \\ 1 Swire Institute of Marine Sciences and School of Biological Sciences, The University of Hong Kong, Hong Kong, China, \\ ${ }^{2}$ Department of Biological Sciences, Clemson University, Clemson, SC, USA, ${ }^{3}$ Department of Marine Biodiversity Research, \\ Japan Agency for Marine-Earth Science and Technology, Yokosuka, Japan, ${ }^{4}$ Advanced Material Research Laboratory, \\ Clemson University, Clemson, SC, USA
}

Although space delineation is a well-accepted requirement for biologically controlled biomineralization, the actual location of the mineralizing compartment within marine invertebrates has only recently been determined. We observed that the biomineralization was compartmented within the collar region of the metamorphosing larvae of Hydrodies elegans at its earliest possible time, i.e., at the post-metamorphic stage. We have also found that these highly regulated compartments contained aragonite crystals, as detected by EBSD and confirmed by electron diffraction TEM. Within these compartments, the metamorphosed larvae maintained a pH 9, at the pKa for $\mathrm{CaCO}_{3}$ formation. This model describes how biomineralization is a space delineation event in which calcium carbonate formation is an intracellular phenomenon.

Keywords: tubeworms, biomineralization, internal pH, FIB-TEM, calcification, aragonite, electron diffraction

Significance statement: Using the tubeworm, a popular invertebrate model for marine research, we propose a unifying mechanism of calcification that emphasizes the importance of specialized mineralizing compartments in providing delineated space for controlled biomineralization within a multicellular organism. Through the use of correlative microscopy, we have demonstrated the functional observation of organisms under fluorescent microscopy can be directly followed by performing structural analysis using the extreme edge of electron microscopy, specifically SEMEBSD and FIB-TEM. Unlike conventional fluorescent observations that require the use of fixation artifacts that are inevitable in electron microscopy, this novel method of understanding both the function and structure of any calcifying organism avoids such artifacts, while still providing a higher structural resolution.

\section{INTRODUCTION}

Tubeworms from the family Serpulidae belong to a major group of calcifying polychaetes, which produce exquisite tube ultrastructures that display a wide variety of mineralogical properties (Vinn et al., 2008; Smith et al., 2013). Simple calcifying marine organisms such as coccolithophores, calcareous green algae, and foraminifera have been the popular candidates in biomineralization research (de Nooijer et al., 2009; Lohbeck et al., 2014; Wizemann et al., 2015). Among the 
more complex calcifying marine animals such as mollusks and echinoderms, the serpulid worms is a taxonomically disctinctive group of calcifiers, and it produces considerable biomass in both facilitating marine species in the temperate waters, and creating biofouling concerns in global oceans (Qiu et al., 2003; Smith et al., 2013). Although, the process of serpulid tube deposition was the subjected of a few early studies, the true origin of crystals remained a mystery. For example, Hedley (1956a,b) described a pair of calcium secretion glands under the fold of the collar region of the tubeworm which involved crystal deposition via secretory mechanisms (Neff, 1969, 1971; Nott and Parkes, 1975). During tube formation, mucus-rich calcium carbonate is secreted in the form of a slurry in which the collar tissues acted like a mold for accumulation and solidification (Hedley, 1956a,b). While this model explains the accretion of irregularly oriented tube ultrastructures that are found in approximately half (54\%) of the serpulid species studied (Vinn et al., 2008), further examination is necessary to explain the construction of many diverse oriented tube structures that are present in many serpulid species (Vinn et al., 2009).

One of the primary requirements for calcification in marine invertebrates is the presence of a compartmentalized space in which the reaction conditions can support calcium carbonate formation (Lowenstam and Weiner, 1989). For example, foraminifera has a great level of biological control in its mineralization. Calcium and carbon pools are present for calcification of the new calcium carbonate chambers (Erez, 2003), and the deposition of mineral involves tiny membrane bound vesicles (Spero, 1988; Bentov and Erez, 2005; de Nooijer et al., 2014) which were later found to be an active cellular process of endocytosis and exocytosis (Bentov et al., 2009). Elucidating these calcification pathways in the living tubeworm requires understanding the movement of the cation $\mathrm{Ca}^{2+}$ and anion $\mathrm{HCO}_{3}^{-}$lattice ions from their source to the crystal product $\mathrm{CaCO}_{3}$ (Weiner and Addadi, 2011). To meet the conditions of $\mathrm{CaCO}_{3}$ nucleation, the calcification environment must maintain a suitable alkaline $\mathrm{pH}$ to favor crystal formation. An elevation of intracellular $\mathrm{pH}$ indicates a favorable deprotonation of the anion $\mathrm{HCO}_{3}^{-}$into $\mathrm{CO}_{3}^{2-}$, and as the $\mathrm{pH}$ approaches $9.0\left(\mathrm{CaCO}_{3}\right.$ $p \mathrm{Ka}=9.0$ ), the precipitation of $\mathrm{CaCO}_{3}$ is favored (Stumm and Morgan, 1996). This formation is achieved through the elimination of hydrogen ions that are generated during the process of $\mathrm{CaCO}_{3}$ formation (Jokiel, 2011). Therefore, empirical observations of the in vivo cellular environment in terms of $\mathrm{Ca}^{2+}$ concentration and $\mathrm{pH}$ distribution during active calcification are crucial for understanding both the lattice ion movements, and the $\mathrm{CaCO}_{3}$ formation. To obtain such information, we used calcein as a putative $\mathrm{CaCO}_{3}$ indicator and employed ratiometric fluorescent molecules in the living larval worm as reporters of cellular $\mathrm{pH}$, both techniques are widely used for understanding the physiological status of many organisms (Moran, 2000; Han and Burgess, 2010).

Many calcifying organisms have been shown to regulate intracellular $\mathrm{pH}$, which occurs in the foraminifera (de Nooijer et al., 2008; Bentov et al., 2009), and corals (Venn et al., 2013), and is crucial for the construction of biomineral structures. Some calcifiers are known to mitigate the unfavorable environmental $\mathrm{pH}$ in this intracellular context, e.g., coral (Venn et al., 2009) and urchin (Stumpp et al., 2012). Although, scanning electron microscopy (SEM) and transmission electron microscopy (TEM) are effective at characterizing such mineral the samples must be meticulously prepared before these higher resolution-imaging techniques may be used (Hayat, 2000). Therefore, SEM and TEM can only be used in characterization of non-living specimens. Since calcein may be ineffective at an alkaline pH, SEMEDX was applied correlatively characterize the distribution of calcium. Consequently, there is a need to integrate the in vivo information of the cellular process derived from fluorescence microscopy with the holistic picture of these minerals derived from electron microscopy to fully characterize calcification mechanisms.

Serpulid larvae are ideal for use in studying biomineralization in that the tube formation of these calcifiers begins at the time of metamorphosis, thus marking the important transition from free-swimming larvae into sessile reef-building adults (Carpizo-Ituarte and Hadfield, 1998). Calcification occurs immediately after the attachment and metamorphosis of the tubeworm, thus providing an optimum window for in vivo fluorescent microscopic examination. Larval metamorphosis of the tubeworm provides an optimum window undertaking calcification studies without the requirement of using such artificial treatments such as decalcification. The research team used the tubeworm Hydroides elegans for this study in that it has a well-understood life cycle to facilitate the direct observation of the earliest onset of biomineralization within a predictable temporal frame of reference.

In this study, the actively calcifying post-metamorphic stages of Hydroides elegans, were monitored with correlative microscopy. This method of understanding both the function and structure of any calcifying organism is novel in that it avoids the introduction of inevitable fixation artifacts in electron microscopy, which includes uneven penetrative rate of fixative in the tissue, differences in fixative reaction with different cellular components, and drying conditions when tissues were not totally immersed in fixative (Wisse et al., 2010), while also providing a higher structural resolution than conventional fluorescent observations. This experiment entailed using (1) fluorescent microscopy for in vivo observation of the intracellular $\mathrm{pH}$ in the post-metamorphic worm at the earliest onset of calcification and for quantifying this in vivo data to determine the potential calcification compartments and their distribution in the organism; (2) energy dispersive spectroscopy-scanning electron microscopy (EDS-SEM) to map the distribution of calcium ions from putative mineralizing compartment locations; (3) electron backscatter diffraction analysis-scanning electron microscopy (EBSD-SEM) to determine the presence of aragonite crystals within the mapped compartments on unpolished intact specimens using EBSD-SEM; (4) the focused ion beam (FIB) lift-out technique remove of the crystal from the mineralization compartment and confirm the presence of crystalline aragonite; and (5) intermediate voltage TEM to collect the electron diffraction pattern. 


\section{MATERIALS AND METHODS}

\section{Study Material}

Adult Hydroides elegans were obtained from submerged rafts at a fish farm in Clear Water Bay in Hong Kong SAR. Larvae were spawned and raised in the laboratory. Briefly, individuals of $H$. elegans were cleaned to removed any adhered macrofauna, and were placed in separate petri dishes of filtered seawater (FSW; $0.22 \mu \mathrm{m}$ ), eggs and sperm were spontaneously released from broken tubes with exposed posterior ends according to previous reported methods (Bryan et al., 1998; Qiu and Qian, 1998). Gametes from multiple male and female individuals $(\sim 8$ individuals for each sex) were collected and kept separately in small beakers. Several drops of sperm suspension were added to the container with the mixture of eggs to minimize chances of polyspermy. Fertilized eggs were transferred to a larger beaker at a lower density (10 embryos per $\mathrm{mL}$ ) after about $15 \mathrm{~min}$ of fertilization. Trochophore larvae were hatched after $12 \mathrm{~h}$. The newly hatched trochophore larvae were freeswimming and were fed with Isochrysis galbana $\left(6 \times 10^{5}\right.$ cells $\mathrm{mL}^{-1}$ ) with aerated filtered seawater (FSW) renewed every other day $\left(22^{\circ} \mathrm{C}, 33 \%\right.$ o $\left.\mathrm{pH} 8.1\right)$, seawater $\mathrm{pH}$ measured in NBS scale by Mettler-Toledo $\mathrm{pH}$ meter, calibrated with MettlerToledo buffers at $\mathrm{pH} 4, \mathrm{pH} 7$ and $\mathrm{pH}$ 10. Swimming competent larvae on day 8 after hatching were incubated in (1) $10 \mathrm{mg} / \mathrm{L}$ calcein (Bis[N,N-bis(carboxymethyl)aminomethyl]-fluorescein) and (2) $10 \mu \mathrm{M}$ 5-(and-6)-carboxy SNARF-1 acetoxymethyl ester (carboxy SNARF-1 AM, Molecular Probes) in FSW with a salinity of $33 \%$ and a $\mathrm{pH}$ of 8.1 . Calcein stock solution $(500 \mathrm{mg} / \mathrm{L}$, adjusted to $\mathrm{pH} 8.0$ ) was prepared for the experiment.

\section{Cellular Environments Labeling with Fluorescent Molecules}

Larvae were incubated in the dark at a low density $(\sim 5$ larvae per $\mathrm{mL}$ ) inside a water-tight container, and then transported to a laboratory for internal $\mathrm{pH}$ measurement in Japan Agency for Marine-Earth Science and Technology (JAMSTEC), Yokosuka, Japan. The containers were insulated with a foam box and multiple layers of clothes to reduce temperature shock during flight $(\sim 5 \mathrm{~h})$ and land transit $(\sim 4 \mathrm{~h})$. For the remaining time of incubation, larvae were kept at $\sim 20^{\circ} \mathrm{C}$ in the laboratory. After $22 \mathrm{~h}$ of fluorescent dye uptake, the larvae appeared active and healthy. Approximately, 10-20 larvae were rinsed twice with filtered artificial seawater (FASW, 35\%, pH 8.3). After arrival at JAMSTEC, seawater $\mathrm{pH}$ measurements were performed in total scale using a $\mathrm{pH}$ meter (Orion 5 star, Thermo Scientific, MA, USA; two point calibrated with 2-amino-2-hydroxymethyl-1,3propanediol ("tris") buffers at $\mathrm{pH} 6.8$ and $\mathrm{pH} 8.1$ ), and placed in glass based dishes with FASW $10^{-4} \mathrm{M}$ isobutylmethylxanthine (IBMX) to induce metamorphosis (Bryan et al., 1998).

\section{Measurement of Cellular Environment}

Incubated larvae were imaged to visualize post-metamorphic changes, using an inverted fluorescent microscope (Axio Observer, Zeiss, Germany) fitted with a filter cube. Filters were used to detect fluorescent signals in terms of internal $\mathrm{pH}$ distribution from carboxy SNARF-1 signal $\left(\lambda_{1}^{\text {exc }}=488 \mathrm{~nm}\right.$, $\left.\lambda_{1}^{\mathrm{em}}=580 \mathrm{~nm}, \lambda_{2}^{\mathrm{exc}}=514 \mathrm{~nm}, \lambda_{2}^{\mathrm{em}}=640 \mathrm{~nm}\right)$ and calcium distribution from calcein signal $\left(\lambda^{\text {exc }}=470 \mathrm{~nm}, \lambda^{\mathrm{em}}=500 \mathrm{~nm}\right.$ emission). Shutter time for imaging ranged from 100 to $300 \mathrm{~ms}$. Z-stack images ( $1 \mu \mathrm{m}$ between each layer) were captured by digital imaging software (Axiovision, Version 4.6). Gray scale images representing the intensities for both signal channels were exported as TIF files from Axiovision software. Using image J (NIH, Bethesda, MD, USA), a composite image was generated by dividing $\lambda_{2}^{\mathrm{em}}$ by $\lambda_{1}^{\mathrm{em}}$ for each layer pixel by pixel (Process/Image Calculator.../image file $640 \mathrm{~nm}$ "divide" image file $580 \mathrm{~nm}$ ), i.e., $640 / 580 \mathrm{~nm}$ ratio. A representative layer containing the most heterogeneity was selected to interpret in greater detail for the distribution of internal $\mathrm{pH}$. Using the relationship between $640 / 580 \mathrm{~nm}$ ratio and $\mathrm{pH}$, a plot profile was constructed to visualize the distribution of internal $\mathrm{pH}$ (Figure 1).

\section{Calibration of between Intracellular and Environmental pH Values}

In situ calibration was performed using similar stages of tubeworm larvae incubated with $10 \mu \mathrm{M}$ carboxy SNARF-1

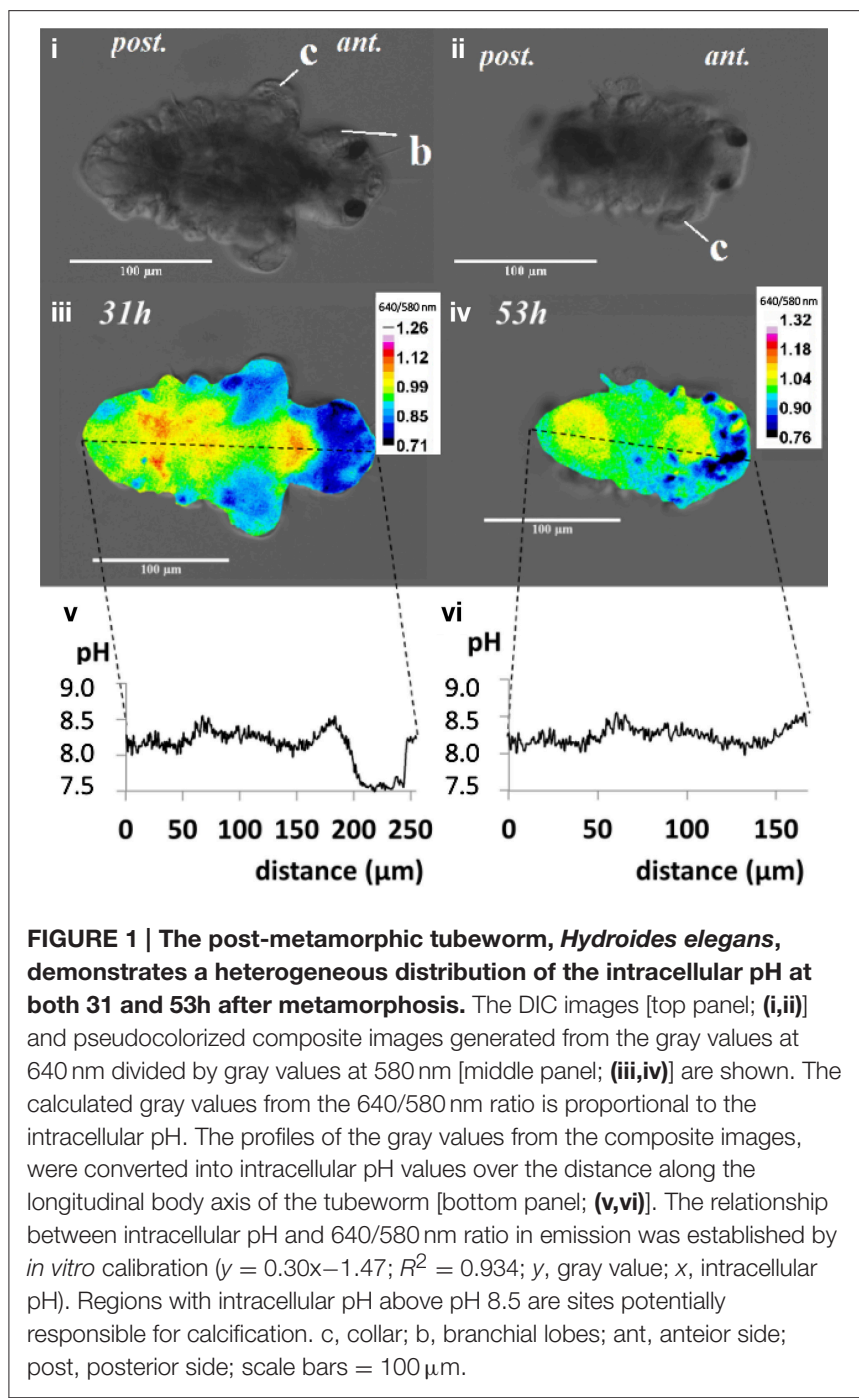


for $22 \mathrm{~h}$. To equilibrate environmental seawater $\mathrm{pH}$ with the intracellular $\mathrm{pH}$, animals were subjected to $50 \mu \mathrm{M}$ nigericin and $150 \mathrm{mM} \mathrm{KCl}$ in AFSW. A relatively higher level of nigericin $(37.3 \mu \mathrm{g} / \mathrm{mL})$ in the presence of $\mathrm{KCl}$ than the minimal nigericin concentration required $(2 \mu \mathrm{g} / \mathrm{mL})$ in previous studies with cell lines was used (Bond and Varley, 2005), with a higher level of nigericin, intracellular and extracellular $\mathrm{pH}$ equilibrium can be ensured in the multicellular larval tubeworm. Cells were in equilibrium with the environmental seawater, and signals intensity for SNARF $640 \mathrm{~nm}$ and $580 \mathrm{~nm}$ appeared homogenous throughout the animal body. The seawater at different $\mathrm{pH}$ was adjusted by $\mathrm{NaOH}$ or $\mathrm{HCl}$ and each $\mathrm{pH}$ value of the seawater environment was recorded using a $\mathrm{pH}$ meter (Orion 5 star, Thermo Scientific, MA, USA; two point calibrated with 2-amino2-hydroxymethyl-1,3-propanediol ("tris") buffers at $\mathrm{pH} 6.8$ and pH 8.1; DelValls and Dickson, 1998). Tubeworm larvae from different seawater $\mathrm{pH}$ environments were imaged and intensities of both 640 and $580 \mathrm{~nm}$, i.e., $\left(\lambda_{2}^{\text {exc }}\right.$ and $\lambda_{1}^{\text {exc }}$ ), were recorded for calculation of the $\mathrm{pH}$ dependent $640 / 580 \mathrm{~nm}$ ratio of carboxy SNARF-1. Realistic values of $\mathrm{pH}$ for physiological range, natural seawater and potential calcification sites, i.e., $\mathrm{pH}$ 5.9-9.9, were used for calibration. The five point calibration showed a linear relationship $\left(y=0.30 \mathrm{x}-1.47 ; y=\right.$ gray value; $x=\mathrm{pH} ; R^{2}=$ $0.934)$. Intracellular $\mathrm{pH}$ values were calculated from the equation using the measured $640 / 580 \mathrm{~nm}$ intensity ratio.

\section{Characterization of Nascent Calcified Products by Scanning Electron Microscopy}

The attached tubeworms at various stages (day 2-4) were preserved with $4 \%$ paraformaldehyde, fixed with osmium tetroxide aqueous solution ( $1 \%$ for $30 \mathrm{~min}$ ) to prevent tissue shrinkage during dehydration process. Serial dehydration with ethanol ( $50 \%$ for $5 \mathrm{~min}$; $70 \%$ for $5 \mathrm{~min}$; $85 \%$ for $5 \mathrm{~min}$; $95 \%$ for $5 \mathrm{~min}$; $100 \%$ for $5 \mathrm{~min}$; $100 \%$ for $5 \mathrm{~min}$ ) was followed by a drying process with 50\% ethanol and 50\% HMDS (until complete evaporation), 100\% HMDS (until complete evaporation). The dried specimen was analyzed using field emission-scanning electron microscopy (FE-SEM) on a SU6600 VPSEM (Hitachi, Japan), at a chamber pressure of $10 \mathrm{~Pa}$ to minimize sample charging. Back-scattered electron (BSE) imaging was then performed at accelerating voltage of $5 \mathrm{kV}$. Energy dispersive Xray spectrometry (EDS) and electron backscattered diffraction (EBSD) data were obtained at $20 \mathrm{kV}$ accelerating voltage. EDS spectra and EBSD patterns were analyzed by AZtec EDS/EBSD microanalysis software (Oxford Instruments).

To determine the potential sites of calcium carbonate deposition, elemental distribution of calcium (Ca) for tubeworms at different post-metamorphic stages was examined by EDS mapping. After the earliest calcified stage was identified, quantitative data from over 30 random spots were collected. Elemental distribution of calcium from a SEM-EDS map was heterogeneous (Figure 2vi). Quantification using EDS spot analysis on multiple locations on the tubeworms found that the calcium rich areas, with over $15 \mathrm{~mol} \mathrm{wt} \%$, were mostly located around the thoracic region (Figure 2vii). Some locations from these calcium rich spots were identified as aragonite crystals by EBSD (Figures 2vii-x). The EBSD specimen was mounted on a $45^{\circ}$ pretilted stub, the unpolished specimen was tilted a further 25 to $\approx 70^{\circ}$ toward the EBSD phosphor screen. EBSD patterns were collected at $100 \mathrm{~ms}$ frame time with $1 \times 1$ binning. Collected Kikuchi bands were automatically detected for certain spots and digitally processed to determine the identity of the mineral phase. Although analysis of a rough, unpolished sample with EBSD was shown to have a limited success rate, the method is nondestructive of the sample, offers a quick and unambiguous way to differentiate mineral phases (Bandli and Gunter, 2012), and provides important spatial information including evidence of probable calcification sites.

\section{Mineralogy Identification by Transmission Electron Microscopy}

Calcified structures emitting a Kikuchi pattern from EBSD analysis were further studied in detail. Bright field highresolution TEM (BR-HRTEM) images were taken by a highresolution transmission electron microscope (HRTEM, Hitachi ${ }^{\circledR}$ TEM H500) with $\mathrm{LaB}_{6}$ source electron gun operated at $300 \mathrm{kV}$. TEM specimens were prepared by a Hitachi NB5000 Focused Ion and Electron Beam (FIB-SEM) system (Hitachi, Japan) with a microsampling system using a gallium ion beam. To prevent charging during fabrication, the samples were sputter-coated with platinum. To minimize beam damage, the region of interest was coated with a thick carbon $(3 \mu \mathrm{m})$ film and a tungsten cap before FIB processing (Figure 3iii). The specimens were trimmed at a lower voltage $(5 \mathrm{kV})$ down to a final thickness of $\sim 200 \mathrm{~nm}$ (Figure 3iv; Kudo et al., 2010); regions that were thin enough were analyzed for TEM.

\section{RESULTS}

When the competent tubeworm larvae were transferred to glass substrates in the presence of $10^{-4} \mathrm{M}$ IBMX, they began metamorphosis from a larval body form into a juvenile body form with branchial radioles (Figures 1i,ii). During this larval metamorphosis process of the tubeworm, both the active processes of cellular control and mineral deposition were observed. The region located near the collar was much higher in $\mathrm{pH}$ compared with other regions. We observed $\mathrm{pH}$ values as high as 9.04 in 3 day post metamorphoric individuals (Supplementary Figure 1). A pH value slightly above the $p \mathrm{Ka}$ value of 9.0 was found to favor the formation of $\mathrm{CaCO}_{3}$ (Figure 2). Regions containing higher $\mathrm{pH}$ values above $\mathrm{pH} 8.5$ included the thoracic and ventral posterior locations of the tubeworm (Figure 1), both of which were also near the specialized cells of the calcifying gland responsible for calcification (Hedley, 1956a,b; Neff, 1969, 1971; Bubel, 1983). This suggests that the tubeworm actively create and maintained cellular environment favorable for calcification. The regions with higher $\mathrm{pH}$ values are generally the thoracic and ventral posterior regions, also correlate with the regions with a high calcein signal (Figures 2i-iv), which in turn suggests the presence of greater calcium ions or newly accreted calcium carbonate. SEM-EDS quantification and mapping (Figures 2vi,vii) provided additional empirical data to suggest these coherent locations of higher $\mathrm{pH}$ values and $\mathrm{Ca}^{2+}$ levels may serves as potential sites for calcification. 


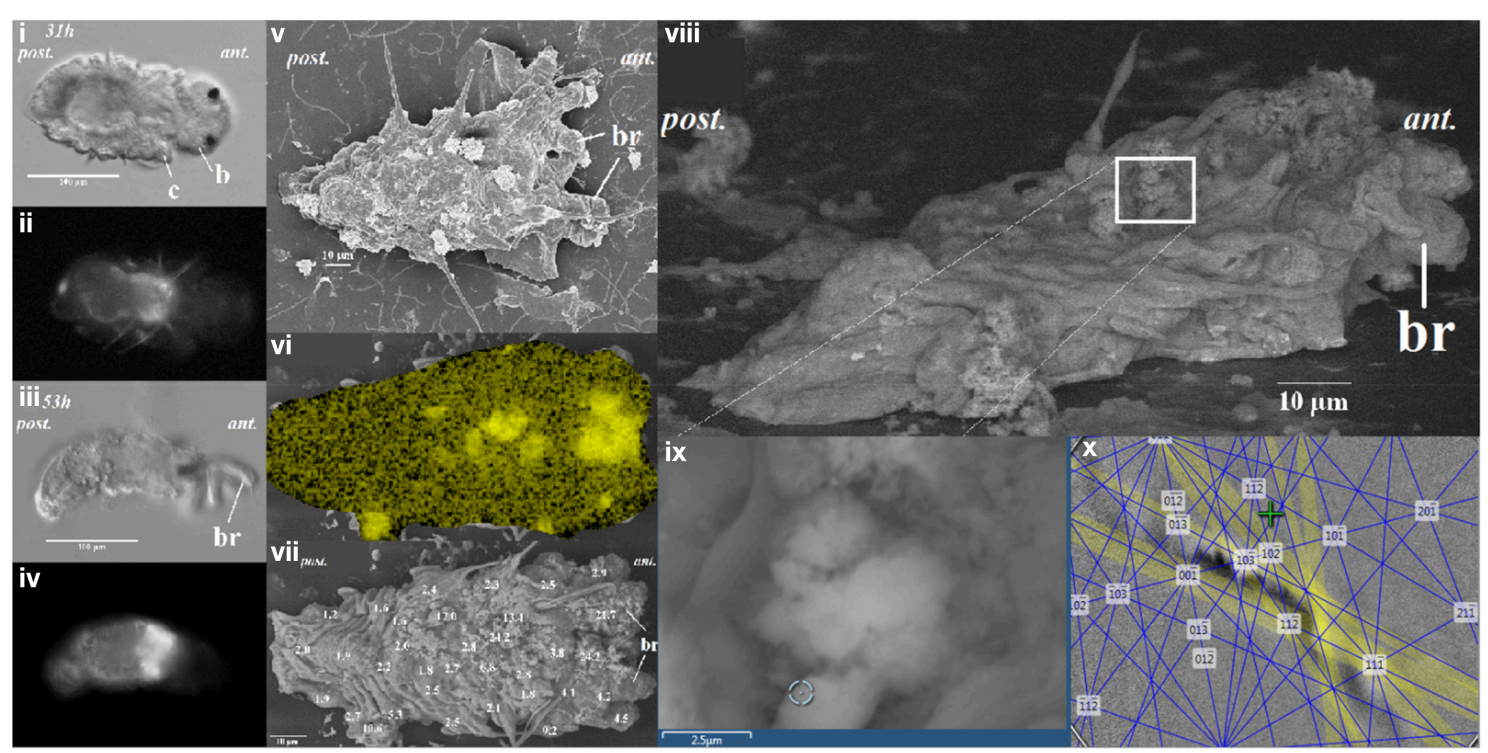

FIGURE 2 | The distribution of calcium ion as correlated to calcein signal at 31 and $53 \mathrm{~h}$ after metamorphosis of the Hydroides elegans. The DIC images [left panel; (i,iii)] and the calcein signal [left panel; (ii,iv)] are shown. Correlative electron microscopy on the day 2 post-metamorphic Hydroides elegans detected spots of calcified structures, as shown in a lower-voltage (5 kV) SEM image [middle panel; (v)]. SEM-EDS analysis mapping, performed at $20 \mathrm{kV}$, shows a heterogeneous distribution of calcium [middle panel; (vi), Ca; in yellow]. The Ca contents are presented as numbers overlaying a greater surface detail of lower-voltage $(5 \mathrm{kV})$ image of the tubeworm, the Ca contents ( $\mathrm{mol}$ wt\%, decimal points are aligned to show the location of spot analyses) obtained from spot quantification (with SEM-EDS at $20 \mathrm{kV}$ [ [middle panel; (vii)]. Regions with a Ca content higher than $15 \mathrm{~mol} w \mathrm{wt} \%$ are likely to be calcified structures. SEM-EBSD analysis of the calcium rich regions is illuastrated in the right panel of (viii-x). The calcium rich regions (white box) as found in SEM-EDS results were further analyzed with EBSD [right panel; (viii)]. (ii) The circle [right panel; (ix)] indicates the EBSD analysis site; a Kikuchi pattern [right panel; (x)] suggests the site is aragonitic from the interface of EDS/EBSD microanalysis software. c, collar; b, branchial lobes; ant, anteior; post, posterior.

A $24 \mathrm{~h}$ incubation period with the two fluorescent dyes, $10 \mu \mathrm{M}$ carboxy SNARF-1 and $10 \mathrm{mg} / \mathrm{L}$ calcein, resulted in no observable impacts on the normal metamorphosis activities of the tubeworm. The tissue of the larvae and algae also exhibited no auto-fluorescence that would have interfered with the detection of $\lambda_{2}^{\text {exc }}$ by $\lambda_{1}^{\text {exc }}$ of carboxy SNARF-1 AM. A few algae in the gut of the tubeworms did contain auto-fluorescence that appeared to overlap with calcein signals, however, the algae appeared as small spheres that were distinctive enough from the tissues and disregarded.

The internal $\mathrm{pH}$ indicator carboxy SNARF-1 AM showed satisfactory cell permeability and effectively labeled the cytoplasm. At a $10 \mu \mathrm{M}$ concentration and incubation time of $22 \mathrm{~h}$, good signal strength was detected from different tissues of the tubeworm. The alteration of the spectral features of carboxy SNARF-1 from the environment of living cells (Han and Burgess, 2010), makes calibration of the live animal tissue essential. The $640 / 580 \mathrm{~nm}$ ratio allows a quantification of $\mathrm{pH}$ in the range between 6.5 and 9.0 with a linear relationship $\left(R^{2}=\right.$ 0.934; Bentov et al., 2009). The quantified $\mathrm{pH}$ values occur within a range that were physiologically realistic for the cytoplasm $(\mathrm{pH}$ $7-8)$, natural seawater ( $\sim \mathrm{pH} 8.1$ ), and potential calcification sites (commonly $>\mathrm{pH}$ 8.5) which are consistent with values found in other calcifiers such as foraminifera and corals (Bentov et al., 2009; Venn et al., 2013).

Elemental quantification using SEM-EDS verified both the presence and absence of crystalline carbonate, which correlated with the regions exhibiting these higher $\mathrm{Ca}^{2+}$ levels (Figures 2vi,vii). These $\mathrm{Ca}^{2+}$ rich areas with over $15 \mathrm{~mol} \mathrm{wt} \%$ calcium were located along the central part of the body (Figure 2). Applied as a non-destructive approach, an intact and unpolished specimen was examined by SEM-EBSD to determine the existence of aragonite in these calcium abundant regions (Figures 2viii-x). A Kikuchi pattern using an unpolished specimen in SEM-EBSD served as an unambiguous and direct evidence of the presence of minerals at selected locations (Bandli and Gunter, 2012). Combining the FIB sample preparation (Figures 3i-iv), the selected-area diffraction pattern detected in a TEM showed evidence of a weak poly-crystalline component arising from aragonite phase (Figure 3), suggesting the formation of aragonite at the early stage of mineralization. Although we characterized the tube material at an early phase, the presence of transiet ACC phase was not detected in the present work.

\section{DISCUSSION}

In this study, a combination of imaging systems, i.e., fluorescent, electron, and X-ray, were applied to identify and study the tissues of interest, correlative microscopy is also an emerging field of research interest (Loussert and Humbel, 2015). We demonstrated how new techniques including a whole animal and a FIB prepared TEM specimen can be analyzed by SEMEBSD and TEM, respectively. These methods were helpful in determining changes in the lattice ion concentration flux 


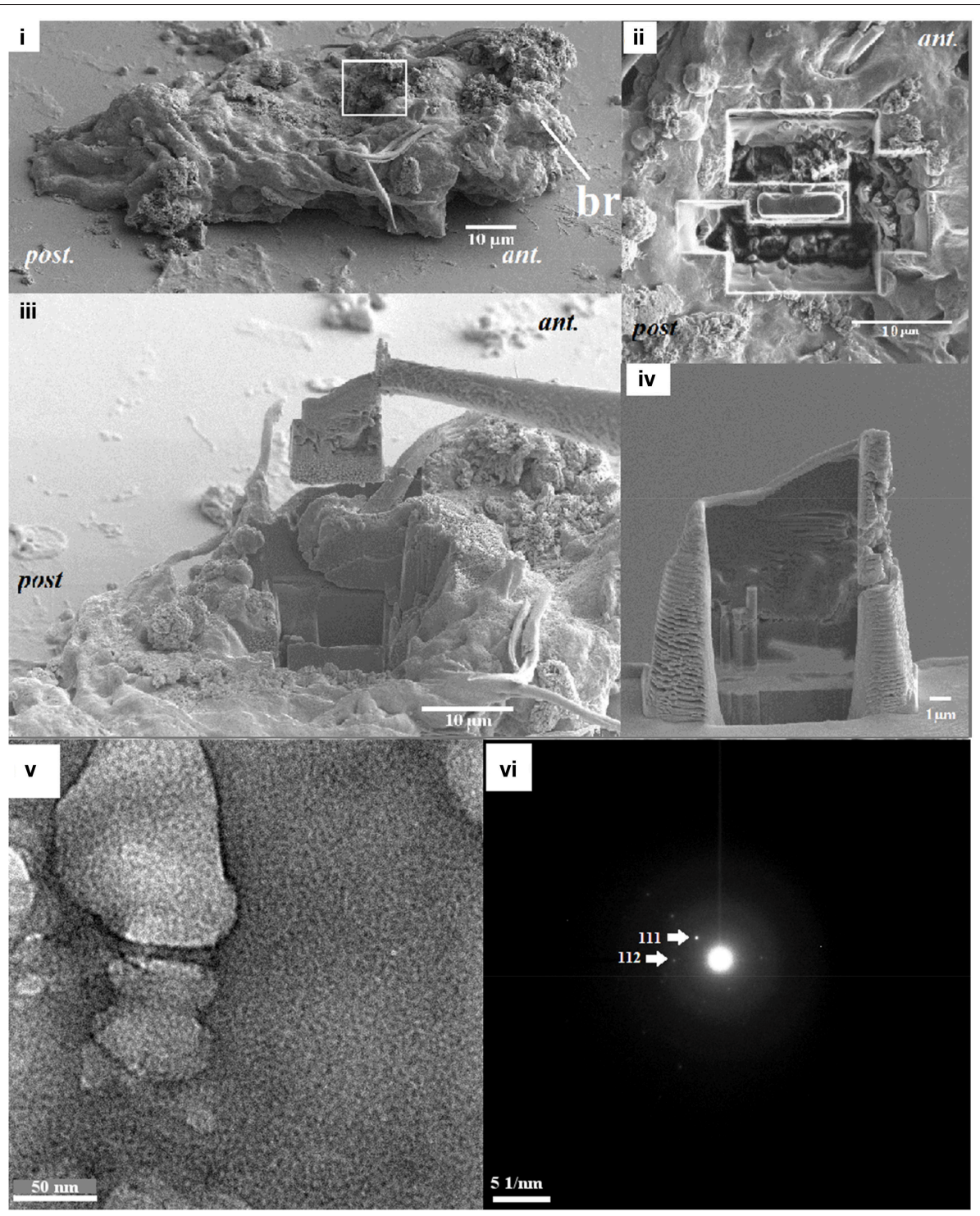

FIGURE 3 | (i) EBSD analysis (white box) showing the region with a Kikuchi pattern was excied to prepare a TEM sample, (ii) the removed surrounding material excised by a focused ion beam (FIB) technique (top view), (iii) the material was lifted using a tungsten probe (side view), (iv) the sample with a final thickness of $\sim 200 \mathrm{~nm}$, which was obtained at a lower voltage. Circled area in (v) were analyzed for the presence of selected-area diffraction pattern in a TEM (vi), showing a single-crystal pattern of aragonite.

and other changes in the mineralization compartment when active mineralization occurs. The process begins with the active regulation of increased intracellular $\mathrm{pH}$, a process known to require the active pumping of protons out of the cell membrane. We constructed a hypothetical model for determining larval tubeworm calcification based on our current knowledge and the serpulid literature (Figure 4). This model localizes the site of biomineralization to the mineralizing compartments, where the calcifying glands (CG) were previously observed at the collar region (Hedley, 1956a,b; Neff, 1971). The gut $(G)$ is described as the site of $\mathrm{Ca}^{2+}$ accumulation, possibly from dietary intake (Nott and Parkes, 1975), which supplies $\mathrm{Ca}^{2+}$ to the calcifying gland (Figure 4ii), resulting in the secretion of calcium carbonate $\left(\mathrm{CaCO}_{3}\right)$ crystals together with mucous organic matter (Figure 4iii). From the early literature, the involvement of multivesicular bodies in the Golgi-rich region of the cells (Neff, 1969)were found to result in an intracellular deposition of calcified crystal granules (de Nooijer et al., 2009). The presence of these intracellular secretory vacuoles suggests calcification is a compartmentalized process (Figure 4iv) and may serve to prevent cytotoxicity in the cytosol associated with $\mathrm{Ca}^{2+}$ build up during $\mathrm{CaCO}_{3}$ precipitaion (Simkiss and Wilbur, 1989).

Space delineation is a well-accepted requirement for biologically controlled mineralization (Simkiss and Wilbur, 1989), however, it remains poorly understood. In the present study, we have observed that biomineralization is 
compartmented within the collar region of the settling marine larvae of Hydrodies elegans and at its earliest possible time, i.e., the post-metamorphic stage. We have also demonstrated that these compartments contain aragonite crystals, as detected by EBSD and confirmed by electron diffraction TEM. Within this highly regulated compartment, the $\mathrm{pH}$ values were elevated to approach the $p \mathrm{Ka}$ value of $\mathrm{CaCO}_{3}$, for purposes of initiating their formation chemically. We observed, through the use of a variety of correlative microscopy techniques, the calcification of aragonite at the earliest possible time, i.e., at the post-metamorphic stage. Our study shows lattice ion concentration flux and changes in the internal $\mathrm{pH}$ environment as active mineralization occurs. It is reasonable to then assume that, if the tubeworm has evolved a functional biomineralizing compartment that meets all physicochemical and thermodynamics constraints of calcium carbonate formation, the most favorable final phase produced formed within the tubeworm would be a crystalline product. Our observation of the existence of aragonite crystals supports this hypothesis.

With regard to the mechanism of nucleation within the compartment it is conceivable that crystallization may undergo an amorphous transient or intermediate phase (Addadi et al., 2003; Pouget et al., 2009) because of the near certain presence and close association of amorphous calcium carbonate (ACC) with the compartmented polycrystalline inclusions that we detected. Although aragonite was detected by EBSD in the collar region of the tubeworm, other calcium rich regions, greater than $15 \mathrm{~mol}$ wt\% along the central part of the animal's body likely held amorphous $\mathrm{CaCO}_{3}$. These findings are consistent with our previous research which showed that the homogenized powder samples of newly deposited tubes also contained amorphous calcium carbonate (ACC) phase (Chan et al., 2015). It is also possible that both crystals and amorphous deposits may be present at the mineralization front (Kudo et al., 2010). It is also now known that the deposition of $\mathrm{CaCO}_{3}$ may be supplied from the intracellular calcification to the body surface via exosomelike crystal bearing vesicles (Figure 4iv; Zhang et al., 2012; Johnstone et al., 2015). These observations have led us to further hypothesize that amorphous materials may act as a supply of lattice ions to enable rapid crystalline growth to the preformed crystals that have been previously deposited by the calcifying tubeworm. This hypothesis can be supported by the model of endoskeleton formation in sea urchin embryos, where aggregates of ACC were found in 20-30 nm nanospheres that integrates to a preformed spicule during its growth (Vidavsky et al., 2014).

The biological production of $\mathrm{CaCO}_{3}$, which is shown in our proposed model, requires the reactants of $\mathrm{HCO}_{3}^{-}$and $\mathrm{Ca}^{2+}$ (Roleda et al., 2012). Despite the uncertainty of its origin (i.e., environmental or metabolic), carbon dioxide $\left(\mathrm{CO}_{2}\right)$ can enter a calcification compartment by diffusion prior to conversion by carbonic anhydrase into $\mathrm{HCO}_{3}^{-}$(Freeman and Wilbur, 1948; Bertucci et al., 2013). The translocation of charged ions would involve ATP dependent mechanisms (Gohad et al., 2009). Membrane bound calcium ATPase has been characterized in the pearl oyster and coral (Zoccola et al., 2004; Fan et al., 2007; Moya et al., 2008). The simultaneous supply of the cation reactant $\left(\mathrm{Ca}^{2+}\right)$ and removal of the inhibitory by-product of calcification $\left(\mathrm{H}^{+}\right.$; Jokiel, 2011; Pan et al., 2015), may cause the ATP dependent translocation of $\mathrm{Ca}^{2+}$ to function as an antiport ion pump. That is to say, each molecule of the $\mathrm{Ca}^{2+}$ influx is coupled with the $\mathrm{H}^{+}$efflux (Figure 4iv). The deposition of $\mathrm{CaCO}_{3}$ may be the result of the intracellular calcification to the body surface via the supply by exosome-like crystal bearing vesicles (Figure 4iv; Zhang et al., 2012; Johnstone et al., 2015). Previous research determined that protons $\left(\mathrm{H}^{+}\right)$act as an inhibitory by-product during calcification (Jokiel, 2011), while the $\mathrm{pH}$ elevation indicated an $\mathrm{H}^{+}$efflux, which was an inhibition removal mechanism that encouraged the process of calcification. The ability to maintain intracellular $\mathrm{pH}$ within the biomineralization space strongly influences calcification success, which we demonstrated to be as great as $\mathrm{pH} 9.0$ within the calcifying compartment of the metamorphosed larvae. Since, the $\mathrm{pK}_{2}$ ' for the dissolution of bicarbonate $\left(\mathrm{HCO}_{3}^{-}\right)$to form carbonate $\left(\mathrm{CO}_{3}^{2-}\right)$ in seawater is 9.11 , at least $50 \%$ of the carbon will assume the form of carbonate and thus be available for crystal formation within the compartment (Stumm and Morgan, 1996). Without a direction measurement of physiological environment, the total alkalinity and salinity values were assumed to be similar to the seawater environment. With this assumption, a conservative estimation of DIC, $35 \mathrm{ppt}, 18^{\circ} \mathrm{C}, \mathrm{pCO}_{2}$ at 400 ppm can be performed using CO2SYS (Lewis and Wallace, 1998), at $\mathrm{pH} 9$, the values of $\mathrm{HCO}_{3}^{-}, \mathrm{CO}_{3}^{2-}$ and $\mathrm{CO}_{2}$ were $17187.04,14703.94$, and $10.61 \mu \mathrm{mol} / \mathrm{kg} \mathrm{SW}$, which add up to DIC value of $31,901.59 \mu \mathrm{mol} / \mathrm{kg}$ SW. This concentration of $\mathrm{CO}_{3}^{2-}$ in seawater yields aragonite saturation states of 221, which enables spontaneous homogeneous nucleation of aragonite (Morse and He, 1993). Furthermore, since carbon dioxide freely diffuses across plasma lipid membranes regardless of its source (either environmental or metabolic) and can be directly converted to bicarbonate by carbonic anhydrase activity within a cellular compartment, the inability of calcifiers in maintaining the cellular environmental such as intracellular $\mathrm{pH}$ would indicate failure in calcification. Elevation of intracellular $\mathrm{pH}$, i.e., the removal of protons, is at a cost of somatic energy (Allemand et al., 2011). Therefore, monitoring the intracellular $\mathrm{pH}$ serves as a way assess the cellular and physiological status of the calcifier, which indicates its susceptibility to metabolic stress from ocean acidification (Bach, 2015). For example, both sea urchins and corals exhibit a certain ability of $\mathrm{pH}$ homeostasis that buffers the effects of $\mathrm{CO}_{2}$-driven acidification (Venn et al., 2009; Stumpp et al., 2012). In addition to the monitoring of intracellular $\mathrm{pH}$ and calcium (Hayat, 2000), higher resolution studies should be undertaken to elucidate the activities of vacuolization and endocytosis by applying commercially available fluorescent molecules (Toyofuku et al., 2008; Bentov et al., 2009). Understanding diverse serpulid tubeworms at the calcification sites during ocean acidification may help determine their susceptibility to a changing climate, which is crucial for developing methods to protect the temperate reefs (Smith et al., 2013). Evaluating the calcifying mechanisms of marine invertebrates throughout their life cycle, addressing their potential adaptaion capacity are essential to developing a more informed understanding of their mechanistic vulnerability in the face of the treats of OA, leading to better predictions 


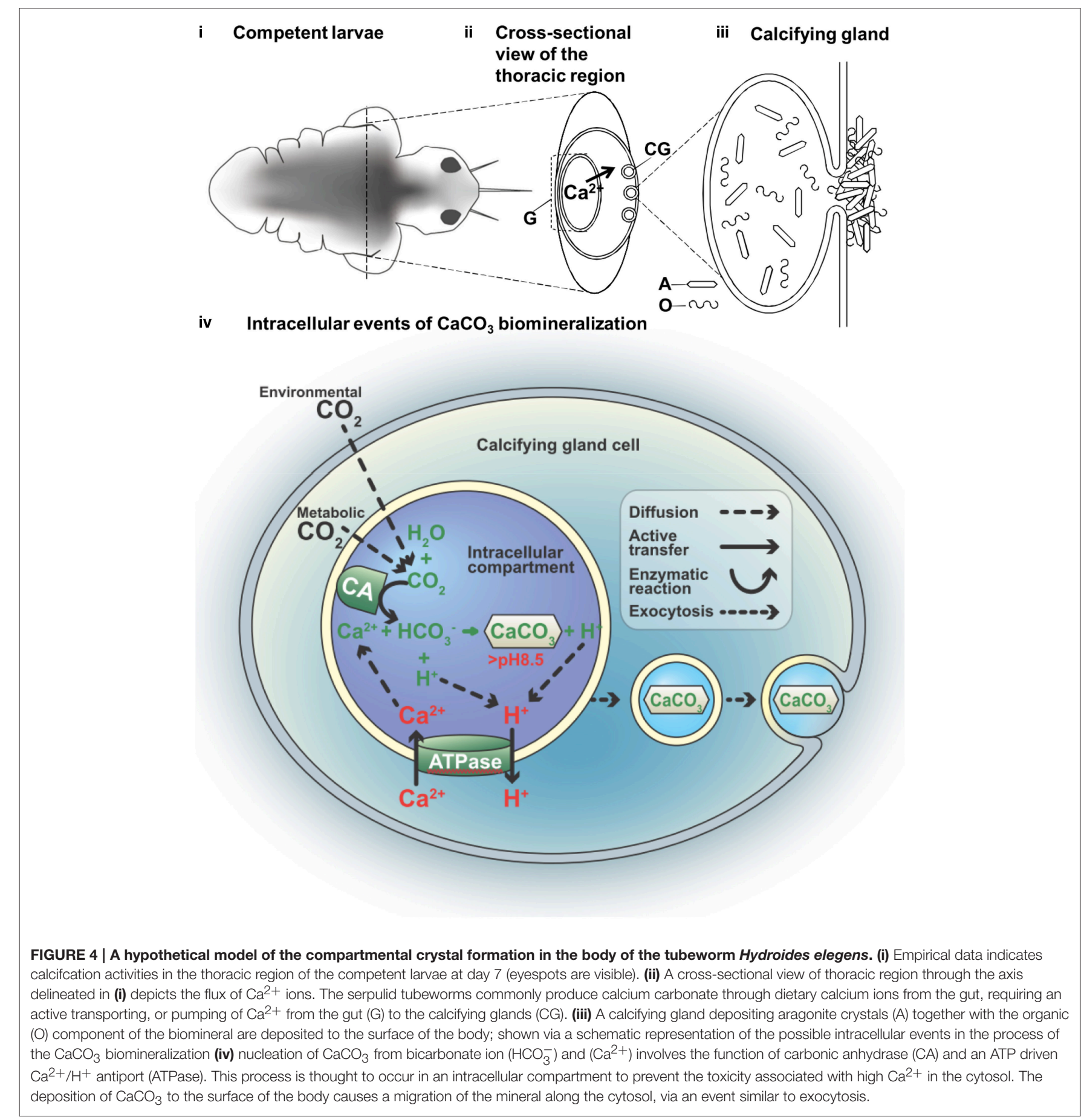

for potential community shifts and reorganization of future ecosystems (Fabry, 2008).

\section{AUTHOR CONTRIBUTIONS}

Research idea contributed by VC, TT, VT, LS, AM. Cultivation and preparation of research animals by VC. Observation of internal $\mathrm{pH}$ by VC and TT. Sample preparation and analysis on SEM-EDX, SEM-EBSD, FIB-TEM by VC, AM, and GW.
Interpretation of mineralogy data by VC, LS, and AM. Paper written by VC, commented by TT, VT, LS, GW, edited by AM.

\section{ACKNOWLEDGMENTS}

The authors wish to thank S. Kawada, S. Kubo, J. Hudson, T. Darroudi, D. Mulwee, H. Qian, Y. W. Lam, M. B. Johnstone, C. Campanati, A. C. Lane, and R. Dineshram for their technical 
assistance and scientific advice on this study. The research idea was inspired by Prof. S. Weiner's generous scientific discussion in the 10th ICCBMT meeting. This study was funded by three GRF grants from the HKSAR-RGC (Grant Numbers: 705511P, 705112P, and 17304914).

\section{REFERENCES}

Addadi, L., Raz, S., and Weiner, S. (2003). Taking advantage of disorder: amorphous calcium carbonate and its roles in biomineralization. Adv. Mater. 15, 959-970. doi: 10.1002/adma.200300381

Allemand, D., Tambutté, É., Zoccola, D., and Tambutté, S. (2011). Coral Calcification, Cells to Reefs. Coral Reefs: An Ecosystem in Transition. New York, NY: Springer.

Bach, L. T. (2015). Reconsidering the role of carbonate ion concentration in calcification by marine organisms. Biogeosci. Discuss 12, 6689-6722. doi: 10.5194/bgd-12-6689-2015

Bandli, B. R., and Gunter, M. E. (2012). Electron backscatter diffraction from unpolished particulate specimens: examples of particle identification and application to inhalable mineral particulate identification. Am. Mineral. 97, 1269-1273. doi: 10.2138/am.2012.4155

Bentov, S., Brownlee, C., and Erez, J. (2009). The role of seawater endocytosis in the biomineralization process in calcareous foraminifera. Proc. Natl. Acad. Sci. U.S.A. 106, 21500. doi: 10.1073/pnas.0906636106

Bentov, S., and Erez, J. (2005). Novel observations on biomineralization processes in foraminifera and implications for $\mathrm{Mg} / \mathrm{Ca}$ ratio in the shells. Geology 33, 841-844. doi: 10.1130/G21800.1

Bertucci, A., Moya, A., Tambutté, S., Allemand, D., Supuran, C. T., and Zoccola, D. (2013). Carbonic anhydrases in anthozoan corals-A review. Bioorg. Med. Chem. 21, 1437-1450. doi: 10.1016/j.bmc.2012.10.024

Bond, J., and Varley, J. (2005). Use of flow cytometry and SNARF to calibrate and measure intracellular $\mathrm{pH}$ in NS0 cells. Cytometry $A$ 64, 43-50. doi: 10.1002/cyto.a.20066

Bryan, P. J., Kreider, J. L., and Qian, P. Y. (1998). Settlement of the serpulid polychaete Hydroides elegans (Haswell) on the arborescent bryozoan Bugula neritina (L.): evidence of a chemically mediated relationship. J. Exp. Mar. Biol. Ecol. 220, 171-190. doi: 10.1016/S0022-0981(97)00105-6

Bubel, A. (1983). A fine structural study of the calcareous opercular plate and associated cells a polychaete annelid. Tissue Cell 15, 457-476. doi: 10.1016/00408166(83)90076-9

Carpizo-Ituarte, E., and Hadfield, M. (1998). Stimulation of metamorphosis in the polychaete Hydroides elegans Haswell (Serpulidae). Biol. Bull. 194, 14. doi: $10.2307 / 1542509$

Chan, V. B. S., Vinn, O., Li, C., Lu, X., Kudryavtsev, A. B., Schopf, J. W., et al. (2015). Evidence of compositional and ultrastructural shifts during the development of calcareous tubes in the biofouling tubeworm, Hydroides elegans. J. Struct. Biol. 189, 230-237. doi: 10.1016/j.jsb.2015.01.004

de Nooijer, L., Toyofuku, T., Oguri, K., Nomaki, H., and Kitazato, H. (2008). Intracellular $\mathrm{pH}$ distribution in foraminifera determined by the fluorescent probe HPTS. Limnol. Oceanogr. 6, 610-618. doi: 10.4319/lom.2008. 6.610

de Nooijer, L. J., Spero, H. J., Erez, J., Bijma, J., and Reichart, G. J. (2014). Biomineralization in perforate foraminifera. Earth Sci. Rev. 135, 48-58. doi: 10.1016/j.earscirev.2014.03.013

de Nooijer, L. J., Toyofuku, T., and Kitazato, H. (2009). Foraminifera promote calcification by elevating their intracellular pH. Proc. Natl. Acad. Sci. U.S.A. 106, 15374-15378. doi: 10.1073/pnas.0904306106

DelValls, T. A., and Dickson, A. G. (1998). The pH of buffers based on 2-amino-2hydroxymethyl-1,3-propanediol ('tris') in synthetic sea water. Deep Sea Res. 45, 1541-1554 doi: 10.1016/S0967-0637(98)00019-3

Erez, J. (2003). The source of ions for biomineralization in foraminifera and their implications for paleoceanographic proxies. Rev. Mineral. Geochem. 54, 115-149. doi: 10.2113/0540115

Fabry, V. (2008). Marine calcifiers in a high- $\mathrm{CO}_{2}$ ocean. Science 320, 1020-1022. doi: $10.1126 /$ science. 1157130

\section{SUPPLEMENTARY MATERIAL}

The Supplementary Material for this article can be found online at: http://journal.frontiersin.org/article/10.3389/fmars. 2015.00097

Fan, W., Li, C., Li, S., Feng, Q., Xie, L., and Zhang, R. (2007). Cloning, characterization, and expression patterns of three sarco/endoplasmic reticulum Ca2+-ATPase isoforms from pearl oyster (Pinctada fucata). Acta Biochim. Biophys. Sin. 39, 722-730. doi: 10.1111/j.1745-7270.2007.00330.x

Freeman, J., and Wilbur, K. (1948). Carbonic anhydrase in molluscs. Biol. Bull. 94, 55-59. doi: 10.2307/1538209

Gohad, N., Dickinson, G., Orihuela, B., Rittschof, D., and Mount, A. (2009). Visualization of putative ion-transporting epithelia in Amphibalanus amphitrite using correlative microscopy: potential function in osmoregulation and biomineralization. J. Exp. Mar. Biol. Ecol. 380, 88-98. doi: 10.1016/j.jembe.2009.09.008

Han, J., and Burgess, K. (2010). Fluorescent indicators for intracellular pH. Chem. Rev. 110, 2709-2728. doi: 10.1021/cr900249z

Hayat, M. A. (2000). Principles and Techniques of Electron Microscopy: Biological Applications. Cambridge, UK: Cambridge University Press.

Hedley, R. (1956a). Studies on serpulid tube formation. I. The secretion of the calcareous and organic components of the tube by Pomatoceros triqueter. Q. J. Microsc. Sci. 97, 411-427.

Hedley, R. (1956b). Studies on serpulid tube formation. II. The calcium-secreting glands in the peristomium of Spirorbis, Hydroides and Serpula. Q. J. Microsc. Sci. 97, 421-427.

Johnstone, M. B., Gohad, N. V., Falwell, E. P., Hansen, D. C., Hansen, K. M., and Mount, A. S. (2015). Cellular orchestrated biomineralization of crystalline composites on implant surfaces by the eastern oyster, Crassostrea virginica (Gmelin, 1791). J. Exp. Mar. Biol. Ecol. 463, 8-16. doi: 10.1016/j.jembe.2014.10.014

Jokiel, P. L. (2011). Ocean acidification and control of reef coral calcification by boundary layer limitation of proton flux. Bull. Mar. Sci. 87, 639-657. doi: 10.5343/bms.2010.1107

Kudo, M., Kameda, J., Saruwatari, K., Ozaki, N., Okano, K., Nagasawa, H., et al. (2010). Microtexture of larval shell of oyster, Crassostrea nippona: a FIB-TEM study. J. Struct. Biol. 169, 1-5 doi: 10.1016/j.jsb.2009. 07.014

Lewis, E., and Wallace, D. W. R. (1998). Program Developed for $\mathrm{CO}_{2}$ System Calculations. ORNL/CDIAC-105. Carbon Dioxide Information Analysis Center; Oak Ridge National Laboratory; U.S. Department of Energy, Oak Ridge; Tennessee.

Lohbeck, K. T., Riebesell, U., and Reusch, T. B. H. (2014). Gene expression changes in the coccolithophore Emiliania huxleyi after 500 generations of selection to ocean acidification. Proc. R. Soc. Lond. B Biol. Sci. 281:20140003. doi: 10.1098/rspb.2014.0003

Loussert, F. C., and Humbel, B. M. (2015). Correlative microscopy. Arch. Biochem. Biophys. 581, 98-110. doi: 10.1016/j.abb.2015.05.017

Lowenstam, H., and Weiner, S. (1989). On Biomineralization. New York, NY: Oxford University Press.

Moran, A. (2000). Calcein as a marker in experimental studies newly-hatched gastropods. Mar. Biol. 137, 893-898. doi: 10.1007/s002270000390

Morse, J. W., and He, S. (1993). Influences of T, S and $\mathrm{P}_{\mathrm{CO} 2}$ on the pseudohomogeneous precipitation of $\mathrm{CaCO}_{3}$ from seawater: implications for whiting formation. Mar. Chem. 41, 291-297. doi: 10.1016/0304-4203(93)90261-L

Moya, A., Tambutté, S., Bertucci, A., Tambutté, E., Lotto, S., Vullo, D., et al. (2008). Carbonic anhydrase in the scleractinian coral Stylophora pistillata characterization, localization, and role in biomineralization. J. Biol. Chem. 283, 25475-25484. doi: 10.1074/jbc.M804726200

Neff, J. (1969). Mineral regeneration by serpulid polychaete worms. Biol. Bull. 136, 76-90. doi: 10.2307/1539670

Neff, J. (1971). Ultrastructure of calcium phosphate-containing cells in the serpulid polychaete worm Pomatoceros caeruleus. Calcif. Tissue Res. 7, 191-200. doi: 10.1007/BF02062606 
Nott, J., and Parkes, K. (1975). Calcium accumulation and secretion in the serpulid polychaete Spirorbis spirorbis L. at settlement. J. Mar. Biol. Assoc. U.K. 55, 911-923. doi: 10.1017/S0025315400017793

Pan, T.-C. F., Applebaum, S. L., and Manahan, D. T. (2015). Experimental ocean acidification alters the allocation of metabolic energy. Proc. Natl. Acad. Sci. U.S.A. 112, 4696-4701. doi: 10.1073/pnas.1416967112

Pouget, E., Bomans, P., Goos, J., and Frederik, P. (2009). The initial stages of template-controlled $\mathrm{CaCO}_{3}$ formation revealed by cryo-TEM. Science 323, 1455. doi: 10.1126/science. 1169434

Qiu, J. W., and Qian, P. Y. (1998). Combined effects of salinity and temperature on juvenile survival, growth and maturation in the polychaete Hydroides elegans. Mar. Ecol. Prog. Ser. 168, 127-134. doi: 10.3354/meps168127

Qiu, J. W., Thiyagarajan, V., Leung, A. W., and Qian, P. Y. (2003). Development of a marine subtidal epibiotic community in Hong Kong: implications for deployment of artificial reefs. Biofouling 19, 37-46. doi: 10.1080/0892701021000060851

Roleda, M. Y., Boyd, P. W., and Hurd, C. L. (2012). Before ocean acidification: calcifier chemistry lessons 1. J. Phycol. 48, 840-843. doi: 10.1111/j.15298817.2012.01195. $\mathrm{x}$

Simkiss, K., and Wilbur, K. (1989). Biomineralization: Cell Biology and Mineral Deposition. New York,NY: Academic Press.

Smith, A. M., Riedi, M. A., and Winter, D. J. (2013). Temperate reefs in a changing ocean: skeletal carbonate mineralogy of serpulids. Mar. Biol. 160, 2281-2294. doi: $10.1007 / \mathrm{s} 00227-013-2210-\mathrm{Z}$

Spero, H. J. (1988). Ultrastructural examination of chamber morphogenesis and biomineralization in the planktonic foraminifer Orbulina universa. Mar. Biol. 99, 9-20. doi: 10.1007/BF00644972

Stumm, W., and Morgan, J. J. (1996). Aquatic Chemistry: Chemical Equilibria and Rates in Natural Waters, 3rd Edn. New York, NY: John Wiley \& Sons, Inc.

Stumpp, M., Hu, M. Y., Melzner, F., Gutowska, M. A., Dorey, N., Himmerkus, N., et al. (2012). Acidified seawater impacts sea urchin larvae $\mathrm{pH}$ regulatory systems relevant for calcification. Proc. Natl. Acad. Sci. U.S.A. 109, 18192-18197. doi: 10.1073/pnas.1209174109

Toyofuku, T., de Nooijer, L. J., Yamamoto, H., and Kitazato, H. (2008). Real-time visualization of calcium ion activity in shallow benthic foraminiferal cells using the fluorescent indicator Fluo-3 AM. Geochem. Geophys. Geosyst. 9:Q05005. doi: 10.1029/2007gc001772

Venn, A. A., Tambutté, E., Lotto, S., Zoccola, D., Allemand, D., and Tambutté, S. (2009). Imaging intracellular $\mathrm{pH}$ in a reef coral and symbiotic anemone. Proc. Natl. Acad. Sci. U.S.A. 106, 16574. doi: 10.1073/pnas.0902894106

Venn, A. A., Tambutté, E., Holcomb, M., Laurent, J., Allemand, D., and Tambutté, S. (2013). Impact of seawater acidification on $\mathrm{pH}$ at the tissue-skeleton interface and calcification in reef corals. Proc. Natl. Acad. Sci. U.S.A. 110, 1634-1639. doi: $10.1073 /$ pnas. 1216153110

Vidavsky, N., Addadi, S., Mahamid, J., Shimoni, E., Ben-Ezra, D., Shpigel, M., et al. (2014). Initial stages of calcium uptake and mineral deposition in sea urchin embryos. Proc. Natl. Acad. Sci. U.S.A. 111, 39-44. doi: $10.1073 /$ pnas. 1312833110

Vinn, O., Kirsimäe, K., and ten Hove, H. A. (2009). Tube ultrastructure of Pomatoceros americanus (Polychaeta, Serpulidae): implications for the tube formation of serpulids. Estonian J. Earth Sci. 58, 148-152. doi: 10.3176/earth.2009.2.05

Vinn, O., Mutvei, H., ten Hove, H. A., and Kirsimae, K. (2008). Unique Mg-calcite skeletal ultrastructure in the tube of the serpulid polychaete Ditrupa. Neues Jahrb. Geol. Paläontol. Abh. 248, 79-89. doi: 10.1127/0077-7749/2008/02480079

Weiner, S., and Addadi, L. (2011). Crystallization pathways in biomineralization. Annu. Rev. Mater. Res. 41, 21-40. doi: 10.1146/annurev-matsci-062910-095803

Wisse, E., Braet, F., Duimel, H., Vreuls, C., Koek, G., Olde Damink, S. W., et al. (2010). Fixation methods for electron microscopy of human and other liver. World J. Gastroenterol.?16, 2851-2866. doi: 10.3748/wjg.v16.i23.2851

Wizemann, A., Meyer, F. W., Hofmann, L. C., Wild, C., and Westphal, H. (2015). Ocean acidification alters the calcareous microstructure of the green macroalga Halimeda opuntia. Coral Reefs 34, 941-954. doi: 10.1007/s00338-0151288-9

Zhang, G., Fang, X., Guo, X., Li, L., Luo, R., Xu, F., et al. (2012). The oyster genome reveals stress adaptation and complexity of shell formation. Nature 490, 49-54. doi: 10.1038/nature11413

Zoccola, D., Tambutté, E., Kulhanek, E., Puverel, S., Scimeca, J.-C., Allemand, D., et al. (2004). Molecular cloning and localization of a PMCA P-type calcium ATPase from the coral Stylophora pistillata. Biochim. Biophys. Acta 1663, 117-126. doi: 10.1016/j.bbamem.2004.02.010

Conflict of Interest Statement: The authors declare that the research was conducted in the absence of any commercial or financial relationships that could be construed as a potential conflict of interest.

Copyright (C) 2015 Chan, Toyofuku, Wetzel, Saraf, Thiyagarajan and Mount. This is an open-access article distributed under the terms of the Creative Commons Attribution License (CC BY). The use, distribution or reproduction in other forums is permitted, provided the original author(s) or licensor are credited and that the original publication in this journal is cited, in accordance with accepted academic practice. No use, distribution or reproduction is permitted which does not comply with these terms. 